(A) Check for updates

Cite this: Food Funct., 2018, 9, 4419

\section{Laurus nobilis (laurel) aqueous leaf extract's toxicological and anti-tumor activities in HPV16-transgenic mice}

\author{
B. Medeiros-Fonseca, ${ }^{a, b}$ V. F. Mestre, ${ }^{a, b}$ B. Colaço, (iD ${ }^{a, c}$ M. J. Pires, (iD ${ }^{a, b}$ \\ T. Martins, (ID a,b R. M. Gil da Costa, (D) a,d,e M. J. Neuparth, ID f,g R. Medeiros, (ID e,h,i,j \\ Magda S. S. Moutinho, a,b Maria Inês Dias, (iD k Lillian Barros, (iD k \\ M. M. S. M. Bastos, (iD d L. Félix, (iD a C. Venâncio, (iD ${ }^{a, c}$ Isabel C. F. R. Ferreira, (iD ${ }^{k}$ \\ L. M. Antunes (iD ${ }^{a, b}$ and P. A. Oliveira iD *a,b
}

\begin{abstract}
Cancers induced by human papillomavirus (HPV) infection remain a significant public health threat, fueling the study of new therapies. Laurel (Laurus nobilis) compounds and extracts recently showed in vitro activity against HPV-transformed cell lines. This work aims to evaluate the in vivo efficacy and hepatic toxicity of a laurel extract in a transgenic mouse model of HPV16-induced cancer. The extract was administered in drinking water (20 mg per animal per day) for three consecutive weeks, using four experimental groups ( $n=10$ ) (group I: HPV16 ${ }^{-/-}$without treatment, group II: treated HPV16 ${ }^{-/}$, group III: HPV16 $6^{+/-}$ without treatment and group IV: treated $\mathrm{HPV}_{1} 6^{+-}$). Following the treatment period, animals were sacrificed and skin samples were used to classify skin lesions histologically. Toxicological parameters included hematological and biochemical blood markers, splenic and hepatic histology and hepatic oxidative stress. The extract did not prevent the progression of HPV16-induced cutaneous lesions in this model. The treated wildtype animals showed mild hepatitis, while transgenic animals suffered weight loss. However, there were no changes concerning hematological, biochemical and hepatic oxidative stress markers.
\end{abstract}

Received 24th April 2018, Accepted 10th July 2018

DOI: $10.1039 / \mathrm{c} 8 \mathrm{fo} 00783 \mathrm{~g}$

rsc.li/food-function originating from leaves are used as spices and flavoring compounds in the culinary and food industries. ${ }^{1}$ Laurel has great importance due to its diverse medicinal applications. It has been traditionally used to treat gastric problems, such as changes in digestion, eructation and flatulence. ${ }^{2}$ According to Iranian traditional medicine, the leaf essential oil of laurel has been used as an antiepileptic remedy. ${ }^{3}$ These anticonvulsive properties were also evaluated against experimental seizures induced in a mice model. ${ }^{4}$ Laurel is also rich in active substances with antibacterial, antifungal and antitumor properties. ${ }^{5,6}$ In general, most antineoplastic drugs are associated with mild to severe side effects and their use is not always effective. So, there is a worldwide endeavor to discover new antineoplastic drugs from plants used in traditional medicine, which are more effective and more affordable and have fewer side effects. ${ }^{7}$ Many substances isolated from plants, or plant extracts, show anti-neoplastic activity. These are often antioxidant and anti-inflammatory substances like curcumin and quercetin. ${ }^{8} \quad$ Ginger (Zingiber officinale), ${ }^{9}$ cinnamon (Cinnamomum spp.), ${ }^{10}$ and laurel (Laurus nobilis) extracts also contain substances with anti-oxidant and anti-inflammatory properties. $^{5,6}$ Recently, aqueous and methanolic laurel extracts obtained from wild and cultivated plants showed significant 
in vitro activity against cervical cancer (HeLa) cells transformed by HPV18. ${ }^{11}$ Given these results, an in vivo efficacy study is now desirable, in order to advance the pre-clinical study of these extracts. Accordingly, the present work aims to study the in vivo effects of a laurel aqueous extract, in a transgenic mouse model of cancer induced by the high-risk HPV type 16 (HPV16). Considering that the previous in vitro study also showed some hepatocellular toxicity, multiple in vivo toxicological parameters were also studied. The mouse model chosen for this purpose is transgenic for the complete HPV16 early region and develops pre-malignant and malignant lesions at multiple sites. ${ }^{12}$ This model was previously used by our team to test other natural compounds, including vegetable toxins like ptaquiloside from bracken (Pteridium spp. $)^{13}$ and dietary polyphenols like curcumin and rutin. ${ }^{8}$ In these previous studies, these transgenic animals showed a strong predisposition to develop severe hepatic and splenic inflammation, making them a suitable model to test both the efficacy and the potential hepatotoxicity of laurel extracts.

\section{Materials and methods}

\subsection{Sample preparation}

A wild sample of Laurus nobilis L. (laurel fresh leaves) was collected in the autumn of 2012 in Bragança, Portugal. Morphological key characters from the Flora Iberica were used for plant identification. Voucher specimens are deposited in the herbarium of the Escola Superior Agrária de Bragança (BRESA). The sample was lyophilized (FreeZone 4.5, Labconco, Kansas, USA) in order to preserve as much as possible its chemical composition until analysis. Afterwards, the sample was reduced to a fine dried powder $(20 \mathrm{mesh})$ and mixed to obtain a homogenate sample and preserved in a container containing silica gel at $-20^{\circ} \mathrm{C}$, until further analysis.

The aqueous extract (infusion) was obtained by adding $1 \mathrm{~L}$ of boiling distilled water to $10 \mathrm{~g}$ of the powdered plant material. Afterwards, the mixture was left to stand at room temperature for $5 \mathrm{~min}$, filtered under reduced pressure, frozen, and then lyophilized to obtain a powder dry extract. $^{14}$

The extract was further dissolved in water at a concentration of $20 \mathrm{mg} \mathrm{mL} \mathrm{m}^{-1}$, based on the phenolic compound concentration in this solution $\left(336 \mu \mathrm{g} \mathrm{mL}^{-1}\right)$ and on the $\mathrm{GI}_{50}$ value obtained in the in vitro studies performed with HeLa cells $\left(88 \mu \mathrm{g} \mathrm{mL} \mathrm{m}^{-1}\right) .{ }^{11}$ Taking into account these values, it was decided to give $4 \times$ the concentration of the $\mathrm{GI}_{50}$ value to guarantee the phenolic compound concentration. The solution was renewed every 3 consecutive days for the in vivo studies.

2.1.1. Phenolic compounds profile and stability of the aqueous extracts. The phenolic compounds were determined in a Dionex Ultimate 3000 UPLC (Thermo Scientific, San Jose, C A, USA), equipped with a diode-array detector (DAD, 280, 330 and $370 \mathrm{~nm}$ as preferred wavelengths), and a mass detector equipped with an ESI source (Linear Ion Trap LTQ XL, Thermo
Finnigan, San Jose, CA, USA). The identification of the different phenolic compounds was performed by comparison with available commercial standards, or tentatively identified using reported data from the literature. For quantitative analysis, a calibration curve for each available phenolic standard was constructed based on the UV signal or when no commercial standard was available, a similar compound from the same phenolic group was used as a standard ${ }^{15}$ and the results were expressed in $\mu \mathrm{g}$ per $\mathrm{mL}$ of infusion.

The stability of the drinking water was evaluated for 5 consecutive days, at room temperature. In this study, the aqueous extract was prepared at the feeding concentration and analyzed daily through an LC-DAD-ESI/MS system, to visualize if there was degradation of any compounds.

\subsection{Mice}

For the accomplishment of this experimental work, forty female Mus musculus of the $\mathrm{FVB} / \mathrm{n}$ strain were used: twenty transgenic (hemizygotic HPV16 ${ }^{+/}$) and twenty wild-type (homozygous $\mathrm{HPV}^{-/-} 6^{-}$) mice aged 20-22 week-old. At this age, cutaneous lesions on this mouse strain start progressing from the hyperplastic to the dysplastic stage, providing an opportunity to experimentally block this progression. Female mice were selected in order to minimize aggressive behavior between animals, frequently observed in male animals. The mouse strain was generously donated by Drs Jeffrey Arbeit and Douglas Hanahan from the University of California, through the National Cancer Institute Mouse Repository (USA). The animals were genotyped using a polymerase chain reaction technique, as previously described. ${ }^{16,17}$

\subsection{Experimental procedures}

The animals were kept according to the national legislation (Decree-Law 113/2013, August 7) and European Directive 2010/ 63/EU on the protection of animals for experimentation, after approval by UTAD's Ethics Committee (10/2013) and the Direção Geral de Alimentação e Veterinária (authorization number 0421/000/000/2014). The animals were kept under controlled experimental conditions of temperature $\left(23 \pm 2{ }^{\circ} \mathrm{C}\right)$, light-dark cycle (light between $8.00-20.00 \mathrm{~h}$ ) and relative humidity $(50 \pm 10 \%)$. Throughout the experiment, mice were fed a standard diet (4RF21 GLP, Mucedola, Italy) ad libitum and they drank tap water. Animals were divided into four groups: groups I (HPV16 $\left.{ }^{-/-}, n=10\right)$, II $\left(\mathrm{HPV}_{16} 6^{-/-}, n=10\right)$, III $\left(\mathrm{HPV}_{16}{ }^{+-}, n=10\right)$, and IV (HPV16 $\left.{ }^{+-}, n=10\right)$. Animals from groups II and IV were administered laurel extract in drinking. water at a dose of $20 \mathrm{mg}$ per animal per day, for three consecutive weeks. The animal's weights and their food and water consumption were recorded every five days; at the same time, animals were carefully observed to confirm their well-being. At the end of the third week, all animals were sacrificed by intraperitoneal administration of a mixture of xylazine and ketamine, followed by cardiac puncture exsanguination, according to the FELASA guidelines. ${ }^{18}$ 
2.3.1. Determination of microhematocrit. Blood samples were centrifuged in capillary tubes, using a centrifuge with an adapter for microhematocrit tubes, at $9000 \mathrm{rpm}$ for 5 minutes.

2.3.2. Serum biochemistry. The blood samples were allowed to clot and centrifuged at $3000 \mathrm{rpm}$ for 15 minutes $\left(4^{\circ} \mathrm{C}\right)$. The serum was separated and frozen at $-80{ }^{\circ} \mathrm{C}$ until use. The serum concentrations of creatinine, urea, aspartate aminotransferase (AST), alanine aminotransferase (ALT) and gamma glutamyl transferase (GGT) were determined in an autoanalyzer (Prestige 24i, Cormay PZ).

2.3.3. HPV16-induced lesions. Chest skin samples were fixed in $10 \%$ neutral buffered formalin and paraffinembedded. Histological slides were stained with hematoxylin and eosin (H\&E) for observation under optical microscopy and histological classification, as normal skin, epidermal hyperplasia and epidermal dysplasia, as previously described. ${ }^{8}$ Briefly, epidermal hyperplasia was characterized by an increased number of epidermal layers, with an increased epidermal thickness and normal differentiation. Epidermal dysplasia was diagnosed based on aberrant differentiation, with suprabasal mitotic activity, nuclear pleomorphism, nuclear crowding, aberrant keratinization, disorganization of epidermal layers and sub-epidermal inflammation and neovascularization.

2.3.4. Hepatic and splenic histology. The liver and spleen were selected for histological observation, because these organs have been previously described to suffer from severe inflammation in this animal model, ${ }^{8}$ and are thus particularly susceptible to additional toxic damage. Liver samples were classified as a normal liver or as hepatitis of 3 degrees of increasing severity (grades I, II and III). Grade I hepatitis was characterized by Kupfer cell hyperplasia with the possible presence of multifocal microabscesses. Grade II hepatitis showed moderate to intense, multifocal, mixed periportal leukocytic infiltration. Grade III hepatitis was diagnosed when periportal infiltrates became coalescing, forming bridges between adjacent portal spaces. Splenic samples were classified as a normal spleen, splenic white pulp hyperplasia and granulomatous splenitis. White pulp hyperplasia was characterized by a predominance of white pulp lymphoid tissue over the red pulp, with the formation of prominent germinal centers. The diagnosis of granulomatous splenitis was reserved for lesions showing extensive destruction of the splenic architecture by a diffuse granulomatous reaction with a predominance of macrophages and fibroblasts.

2.3.5. Hepatic oxidative stress. For determining oxidative stress parameters, livers were homogenized in cold buffer solution $\left(0.32 \mathrm{mM}\right.$ of sucrose, $20 \mathrm{mM}$ of HEPES, $1 \mathrm{mM}$ of $\mathrm{MgCl}_{2}$, and $0.5 \mathrm{mM}$ of phenylmethyl sulfonylfluoride PMSF, prepared in ethanol to prevent protein degradation, $\mathrm{pH}$ 7.4), using a motor-driven Teflon and glass Potter-Elvehjem homogenizer. The homogenate was centrifuged at $15000 \mathrm{~g}$ for 20 minutes at $4{ }^{\circ} \mathrm{C}$ (Sigma model 3K30, Osterode, Germany) and supernatants were collected for analysis. The reactive oxygen species (ROS) synthesis was estimated by using a fluorescent 2,7dichlorofluorescein diacetate (DCFDA) probe, following the method previously published ${ }^{19}$ with excitation and emission at
485 and $530 \mathrm{~nm}$, respectively. DCF was used for constructing a standard curve (0-100 nM). The activity of superoxide dismutase $(\mathrm{Cu} / \mathrm{Zn}$-SOD) was determined by the nitroblue tetrazolium (NBT) reduction generated by the xanthine/xanthine oxidase system at $560 \mathrm{~nm} .{ }^{20}$ SOD from bovine erythrocytes was used for constructing a standard curve $\left(0-3.75 \mathrm{U} \mathrm{mL}^{-1}\right)$. The activity of catalase (CAT) was determined at $240 \mathrm{~nm}$ in accordance with a previously published method ${ }^{21}$ and was calculated using bovine catalase as a standard (0-5 $\left.\mathrm{U} \mathrm{mL}^{-1}\right)$. Glutathione peroxidase (GPx) activity was determined at $340 \mathrm{~nm}$ (ref. 22) using the extinction coefficient of $6.22 \mathrm{mM}^{-1} \mathrm{~cm}^{-1}$. Glutathione reductase (GR) activity was determined by measuring the increase in the absorbance of NADPH at $340 \mathrm{~nm}$ (ref. 23) using a molar extinction coefficient of $6.22 \mathrm{mM}^{-1} \mathrm{~cm}^{-1}$. Gluthathione $S$-transferase (GST) activity was determined by the increase in absorbance at $340 \mathrm{~nm}$ due to the conjugation of the thiol group of glutathione to the 1-chloro-2,4-dinitrobenzene (CDNB) substrate, ${ }^{24}$ using the molar extinction coefficient of $9.60 \mathrm{mM}^{-1} \mathrm{~cm}^{-1}$. The glutathione levels were determined by measuring both the reduced (GSH) and the oxidized states (GSSG) using the fluorochrome ortho-phthalaldehyde (OPA), at $320 \mathrm{~nm}$ and $420 \mathrm{~nm}$, for excitation and emission wavelengths, respectively. ${ }^{25}$ Concentrations were estimated based on GSH and GSSG standard curves $(0-10 \mu \mathrm{M})$. The ratio between GSH and GSSG was calculated as the oxidative-stress index (OSI). The malondialdehyde (MDA) content, an indicator of lipid peroxidation (LPO), was measured at $535 \mathrm{~nm}$ (excitation) and $550 \mathrm{~nm}$ (emission) wavelengths, by the thiobarbituric (TBA) acid-based method described elsewhere. ${ }^{26}$ MDA was estimated based on a standard curve (0-4 nM) of malondialdehyde bis (dimethyl acetal).

\subsection{Statistical analysis}

The body weight gain was calculated according to the following formula:

Final body weight - Inicial body weight Final body weight

Statistical analysis was performed using the SPSS program (Statistical Package for Social Sciences, Chicago, IL, USA) version 17. A statistical ANOVA followed by the Bonferroni test was performed, and values of $p<0.05$ were considered statistically significant.

\section{Results}

\subsection{Phenolic composition}

The peak characteristics (retention time, $\lambda_{\max }$ in the UV-Vis, and mass spectral data) and tentative identification of the phenolic compounds present in laurel leaf aqueous extract are presented in Table 1. Thirty-two compounds were detected from which fourteen were flavan-3-ols (i.e., catechins and proanthocyanidins), fourteen were flavonols and four were flavones. These compounds were previously described ${ }^{14}$ in methanol and infusion extracts obtained from laurel leaves, where 


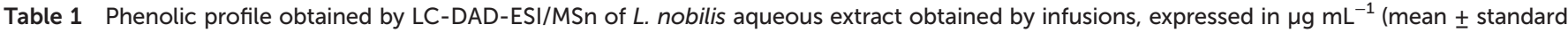
deviation)

\begin{tabular}{|c|c|c|c|c|c|c|}
\hline Peak $^{a}$ & $\begin{array}{l}R_{t}^{a} \\
(\min )\end{array}$ & $\begin{array}{l}\lambda_{\max }{ }^{a} \\
(\mathrm{~nm})\end{array}$ & $\begin{array}{l}\text { Molecular ion } \\
{[\mathrm{M}-\mathrm{H}]^{-a}(m / z)}\end{array}$ & $\operatorname{MS}^{2 a}(m / z)$ & Tentative identification $^{a}$ & $\begin{array}{l}\text { Quantification } \\
\left(\mu \mathrm{g} \mathrm{mL}^{-1}\right)\end{array}$ \\
\hline 1 & 5.1 & 278 & 451 & $289(100)$ & (Epi)catechin-hexoside ${ }^{1}$ & $3.6 \pm 0.1$ \\
\hline 2 & 5.9 & 278 & 451 & $289(100)$ & (Epi)catechin-hexoside ${ }^{1}$ & $22 \pm 1$ \\
\hline 3 & 6.5 & 276 & 305 & $219(13), 179(24), 125(10)$ & $(+)$-Gallocatechin ${ }^{1}$ & $18 \pm 1$ \\
\hline 4 & 7.5 & 278 & 1151 & 865(11), 713(16), 577(7), 575(35), 561(5), 289(44) & Procyanidin tetramer ${ }^{1}$ & $4.65 \pm 0.04$ \\
\hline 5 & 8.0 & 279 & 289 & 245(79), 203(58), $137(24)$ & $(+)$-Catechin ${ }^{1}$ & $19.0 \pm 0.7$ \\
\hline 6 & 8.6 & 280 & 577 & $451(28), 425(60), 407(83), 289(61), 287(13)$ & Procyanidin dimer ${ }^{1}$ & $6.4 \pm 0.1$ \\
\hline 7 & 9.1 & 279 & 577 & 451(49), 425(82), 407(100), 289(69), 287(15) & Procyanidin dimer ${ }^{1}$ & $29 \pm 1$ \\
\hline 8 & 11.0 & 278 & 289 & $245(83), 205(46), 151(24), 137(26)$ & $(-)$-Epicatechin ${ }^{2}$ & $118 \pm 2$ \\
\hline 9 & 11.7 & 276 & 863 & 711(53), 573(27), 451(30), 411(43), 289(22), 285(9) & $\begin{array}{l}\text { Procyanidin trimer } \\
\text { (B- and A-type linkages) }^{1}\end{array}$ & $3.07 \pm 0.02$ \\
\hline 10 & 12.4 & 278 & 863 & 711(46), 573(27), 451(34), 411(46), 289(20), 285(8) & $\begin{array}{l}\text { Procyanidin trimer } \\
\text { (B- and A-type linkages) }^{1}\end{array}$ & $49.3 \pm 0.2$ \\
\hline 11 & 13.7 & 280 & 1153 & 865(9), 713(4), 577(29), 575(14), 561(6), 289(23) & Procyanidin tetramer ${ }^{1}$ & $4.66 \pm 0.06$ \\
\hline 12 & 14.1 & 280 & 1153 & 865(13), 713(9), 577(33), 575(30), 561(5), 289(61) & Procyanidin tetramer ${ }^{1}$ & $9.1 \pm 0.2$ \\
\hline 13 & 14.7 & 280 & 865 & $\begin{array}{l}739(8), 713(17), 695(9), 577(16), 575(25), 425(8), \\
407(16), 289(7), 287(15)\end{array}$ & Procyanidin trimer ${ }^{1}$ & $3.8 \pm 0.1$ \\
\hline 14 & 16.5 & 350 & 447 & $357(72), 327(74), 297(14)$ & Luteolin 6- $C$-glucoside ${ }^{3}$ & $4.69 \pm 0.01$ \\
\hline 15 & 18.1 & 337 & 431 & $341(16), 311(100)$ & Apigenin $8-C$-glucoside ${ }^{4}$ & $1.611 \pm 0.004$ \\
\hline 16 & 18.9 & 280 & 577 & $451(49), 425(85), 407(97), 289(89), 287(22)$ & Procyanidin dimer ${ }^{1}$ & $3.51 \pm 0.02$ \\
\hline 17 & 19.2 & 338 & 577 & $457(8), 413(49), 341(7), 311(6), 293(34)$ & 2"-O-Rhamnosyl- $C$-hexosyl-apigenin ${ }^{4}$ & $2.80 \pm 0.01$ \\
\hline 18 & 19.6 & 355 & 609 & $301(100)$ & Quercetin 3-O-rutinoside ${ }^{5}$ & $0.91 \pm 0.03$ \\
\hline 19 & 20.2 & 336 & 431 & 341(76), 311(100) & Apigenin 6-C-glucoside $^{4}$ & $2.44 \pm 0.07$ \\
\hline 20 & 20.5 & 356 & 463 & $301(100)$ & Quercetin 3-O-glucoside ${ }^{6}$ & $3.9 \pm 0.2$ \\
\hline 21 & 20.9 & 355 & 463 & $301(100)$ & Quercetin $O$-hexoside ${ }^{6}$ & $5.9 \pm 0.2$ \\
\hline 22 & 23.1 & 347 & 593 & $285(100)$ & Kaempferol 3-O-rutinoside ${ }^{7}$ & $1.73 \pm 0.02$ \\
\hline 23 & 23.4 & 344 & 433 & $301(100)$ & Quercetin $O$-pentoside $^{6}$ & $2.078 \pm 0.002$ \\
\hline 24 & 23.6 & 350 & 447 & $285(100)$ & Kaempferol 3-O-glucoside ${ }^{8}$ & $0.99 \pm 0.03$ \\
\hline 25 & 24.2 & 354 & 623 & $315(100)$ & Isorhamnetin $O$-rutinoside ${ }^{9}$ & $3.6 \pm 0.1$ \\
\hline 26 & 24.7 & 348 & 447 & $301(100)$ & Quercetin $O$-rhamnoside ${ }^{6}$ & $5.61 \pm 0.09$ \\
\hline 27 & 25.0 & 356 & 477 & $315(100)$ & Isorhamnetin $O$-hexoside $^{9}$ & $1.01 \pm 0.03$ \\
\hline 28 & 25.6 & 354 & 477 & $315(100)$ & Isorhamnetin $O$-hexoside $^{9}$ & $1.40 \pm 0.03$ \\
\hline 29 & 26.7 & 347 & 417 & $285(100)$ & Kaempferol $O$-pentoside $^{8}$ & $0.62 \pm 0.01$ \\
\hline 30 & 28.5 & 355 & 447 & $315(100)$ & Isorhamnetin $O$-pentoside ${ }^{9}$ & $\operatorname{tr}$ \\
\hline 31 & 29.2 & 343 & 431 & $285(100)$ & Kaempferol $O$-hexoside ${ }^{8}$ & $2.48 \pm 0.03$ \\
\hline
\end{tabular}

Calibration curves: 1 - catechin $\left(y=158.42 x+11.38 ; R^{2}=0.999\right) ; 2-$ epicatechin $\left(y=129.11 x+11.663, R^{2}=0.9999\right) ; 3-$ luteolin-6-C-glucoside $(y=$ $\left.508.54 x-152.82 ; R^{2}=0.997\right) ; 4$ - apigenin-6-C-glucoside $\left(y=223.22 x+60.915, R^{2}=1\right) ; 5$ - quercetin-3-O-rutinoside $\left(y=281.98 x-0.3458 ; R^{2}=1\right) ;$ 6 - quercetin-3-O-glucoside $\left(y=253.52 x-11.615 ; R^{2}=0.999\right) ; 7$ - kaempferol-3-O-rutinoside $\left(y=239.16 x-10.587 ; R^{2}=1\right) ; 8-$ kaempferol-3-O-glucoside $\left(y=288.55 x-4.05 ; R^{2}=1\right) ; 9$ - isorahmetin-3-O-rutinoside $\left(y=327.42 x+313.78 ; R^{2}=0.999\right) .{ }^{a}$ Dias et al. $(2014 \mathrm{~b})^{11,14}$.

(-)-epicatechin was the most abundant compound, as also visualized in the present study.

The stability of these extracts was studied for 5 consecutive days and it was visualized that by day 4 the concentration of phenolic compounds began to decrease (Table 2). Therefore, the feeding water was maintained up to a maximum of 3 days, to avoid degradation of these compounds.

Table 2 Degradation percentage (\%) of the main phenolic compounds in each phenolic group visualized for 5 days

\begin{tabular}{|c|c|c|c|c|c|c|}
\hline Peak & Compound & $\begin{array}{l}\text { Day } \\
1\end{array}$ & $\begin{array}{l}\text { Day } \\
2\end{array}$ & $\begin{array}{l}\text { Day } \\
3\end{array}$ & $\begin{array}{l}\text { Day } \\
4\end{array}$ & $\begin{array}{l}\text { Day } \\
5\end{array}$ \\
\hline 8 & (-)-Epicatechin & 0 & 3.5 & 5.3 & 16.2 & 16.6 \\
\hline 10 & $\begin{array}{l}\text { Procyanidin trimer (B- and } \\
\text { A-type linkages) }\end{array}$ & 0 & 5.3 & 6.0 & 15.8 & 17.3 \\
\hline 14 & Luteolin 6 - $C$-glucoside & 0 & 3.0 & 5.1 & 13.3 & 13.6 \\
\hline 21 & Quercetin $O$-hexoside & 0 & 3.5 & 5.5 & 16.6 & 16.3 \\
\hline
\end{tabular}

\subsection{Mice experiments}

During the experimental work, the animals showed no signs of behavioral change nor did we register mortality. Fig. 1 shows the animals' body weight variation and weight gain for the different groups under study. At the beginning of the experimental work, there were no differences in the mean body weight of the animals distributed by the different groups, but at the end of the study the $\mathrm{HPV}^{+/-}$animals exposed to the laurel extract had a significantly lower body mass, compared with matched controls. Fig. 2 shows the mean values of water and food consumption at the beginning and at the end of the experimental work. Water consumption was higher in $\mathrm{K} 14 \mathrm{HPV} 16^{+/-}$animals, compared with matched wild-type controls, regardless of whether they received laurel treatment. There were no differences between groups concerning food consumption. Table 3 shows the relative weight of the animal's organs, for the different groups under study. Only group IV showed significant differences concerning the weights of the 

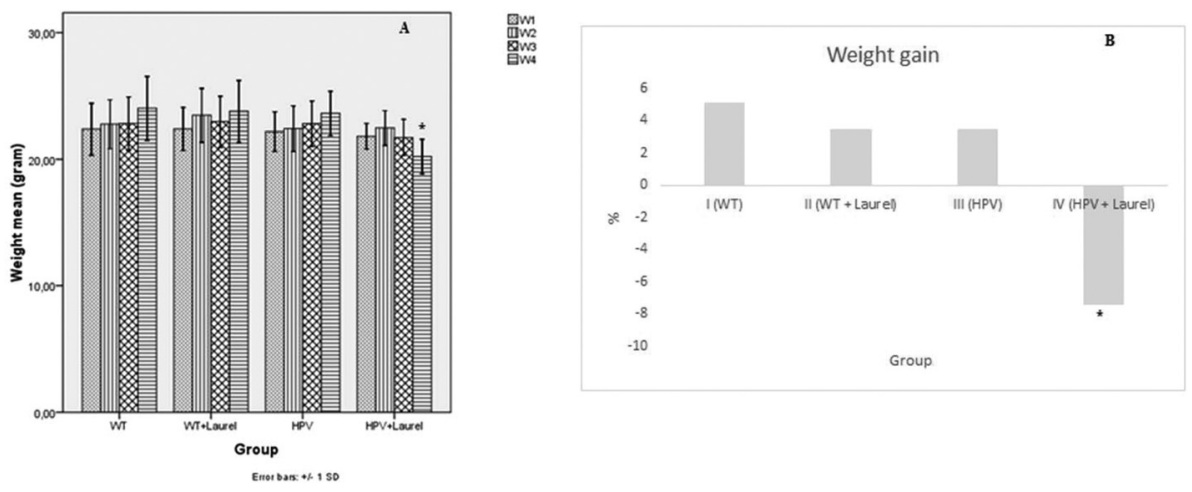

Fig. 1 Body weight variation (A) (mean \pm standard error) and the weight gain (B). W-weight; * $p=0.000$, compared with the other groups.
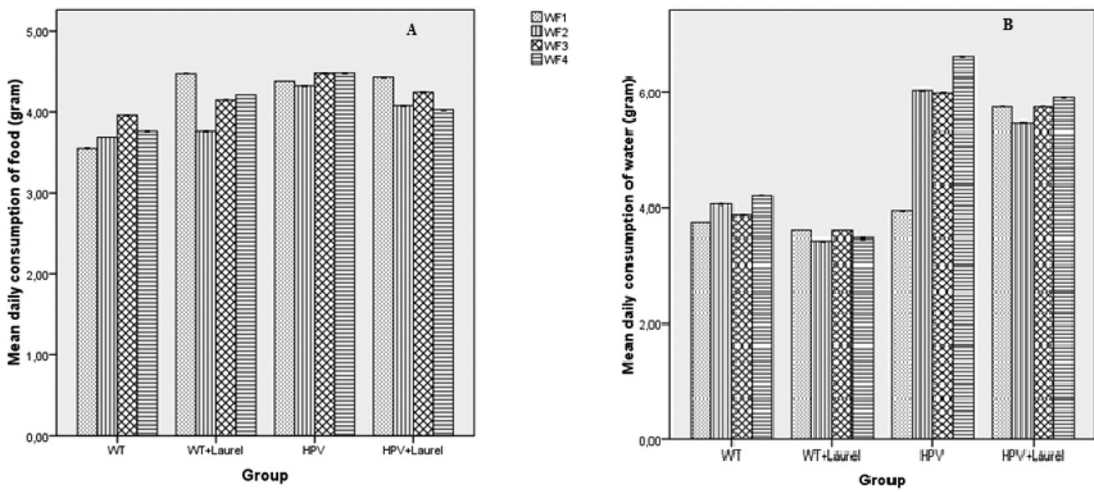

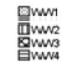

Fig. 2 Mean daily consumption (gram) of food (A) and water (B) per animal in each group. WF-mean food consumption, WW-mean water consumption.

Table 3 Relative weight of the organs in each experimental group (mean \pm standard error)

\begin{tabular}{|c|c|c|c|c|c|c|c|}
\hline Groups & Left kidney & Right kidney & Liver & Spleen & Lungs & Heart & $\begin{array}{l}\text { Urinary } \\
\text { bladder }\end{array}$ \\
\hline I (WT) & $0.0063 \pm 0.0003$ & $\begin{array}{l}0.0065 \pm \\
0.0001\end{array}$ & $0.0538 \pm 0.0013$ & $0.0054 \pm 0.0002$ & $0.0061 \pm 0.0002$ & $\begin{array}{l}0.0065 \pm \\
0.0005\end{array}$ & $0.0047 \pm 0.0004$ \\
\hline II (WT + laurel) & $0.0064 \pm 0.0001$ & $\begin{array}{l}0.0063 \pm \\
0.0002\end{array}$ & $\begin{array}{l}0.06008 \pm \\
0.0021\end{array}$ & $0.0056 \pm 0.0002$ & $0.0069 \pm 0.0002$ & $\begin{array}{l}0.0064 \pm \\
0.0003\end{array}$ & $0.0061 \pm 0.0011$ \\
\hline III (HPV) & $0.0066 \pm 0.0002$ & $\begin{array}{l}0.0070 \pm \\
0.0004\end{array}$ & $\begin{array}{l}0.06116 \pm \\
0.0026\end{array}$ & $0.0062 \pm 0.0004$ & $0.0069 \pm 0.0003$ & $\begin{array}{l}0.0062 \pm \\
0.0003\end{array}$ & $0.0051 \pm 0.0008$ \\
\hline
\end{tabular}

${ }^{a}$ Group IV: $p=0.000$ statistically different from all other groups. ${ }^{b}$ Group IV: $p=0.000$ statistically different from all other groups. ${ }^{c}$ Group IV: $p=$ 0.002 statistically different from groups I and II. ${ }^{d}$ Group IV: $p=0.000$ statistically different from groups I and II.

left kidney, the liver, the spleen and the lungs. From Table 4 we can observe the serum parameters for the different groups under study. Wild-type treated mice show mildly elevated hepatic transaminases compared with untreated controls, although this did not reach statistical significance. Group III showed higher values for urea and creatinine compared with the other groups, which again did not reach statistical significance. Although microhematocrit values were higher in group IV, there were no significant differences between groups (Table 4).
Histological analyses of skin samples from wild-type mice (HPV16 $6^{-/}$) untreated (group I) and treated (group II) showed normal skin histology (Table 5). Group III showed epidermal hyperplasia in $60 \%$ of the mice and lesions of epidermal dysplasia in $40 \%$ of the mice, while group IV showed hyperplasia $(40 \%)$ and more frequent dysplastic lesions (60\%). Fig. 3 shows the representative histological sections of the skin samples in (A) normal skin, in (B) epidermal hyperplasia and in (C) epidermal dysplasia. 
Table 4 Microhematocrit $(\mathrm{Ht})$ and serum parameters evaluated (mean \pm standard error)

\begin{tabular}{|c|c|c|c|c|c|c|}
\hline Groups & Ht (\%) & Creatinine $^{a}$ & Urea $^{a}$ & $\mathrm{ALT}^{b}$ & $\mathrm{GGT}^{b}$ & $\mathrm{AST}^{b}$ \\
\hline I (WT) & 37.95 & $0.6675 \pm 0.2690$ & $79.9750 \pm 12.7943$ & $35.0571 \pm 5.9100$ & $0.2286 \pm 0.2285$ & $43.7111 \pm 16.6996$ \\
\hline II (WT + laurel) & 39.32 & $0.4400 \pm 0.2314$ & $71.0286 \pm 12.6486$ & $37.8800 \pm 11.9807$ & $2.1600 \pm 2.1600$ & $76.0571 \pm 23.3012$ \\
\hline III (HPV) & 43.22 & $0.7467 \pm 0.3690$ & $103.9000 \pm 11.9384$ & $87.6333 \pm 24.9806$ & $0.0000 \pm 0.0000$ & $93.6000 \pm 25.5525$ \\
\hline IV (HPV + laurel) & 45.05 & $0.3686 \pm 0.2054$ & $78.9143 \pm 9.1511$ & $41.4333 \pm 12.9350$ & $0.0667 \pm 0.0666$ & $107.8857 \pm 25.974$ \\
\hline
\end{tabular}

${ }^{a} \mathrm{Mg} \mathrm{dl}^{-1} \cdot{ }^{b} \mathrm{U} \mathrm{L}^{-1}$. ALT-Alanine aminotransferase; GGT-gamma glutamyl transferase; AST-aspartate aminotransferase.

Table 5 Histological classification of skin, liver and spleen lesions in transgenic and wild-type mice

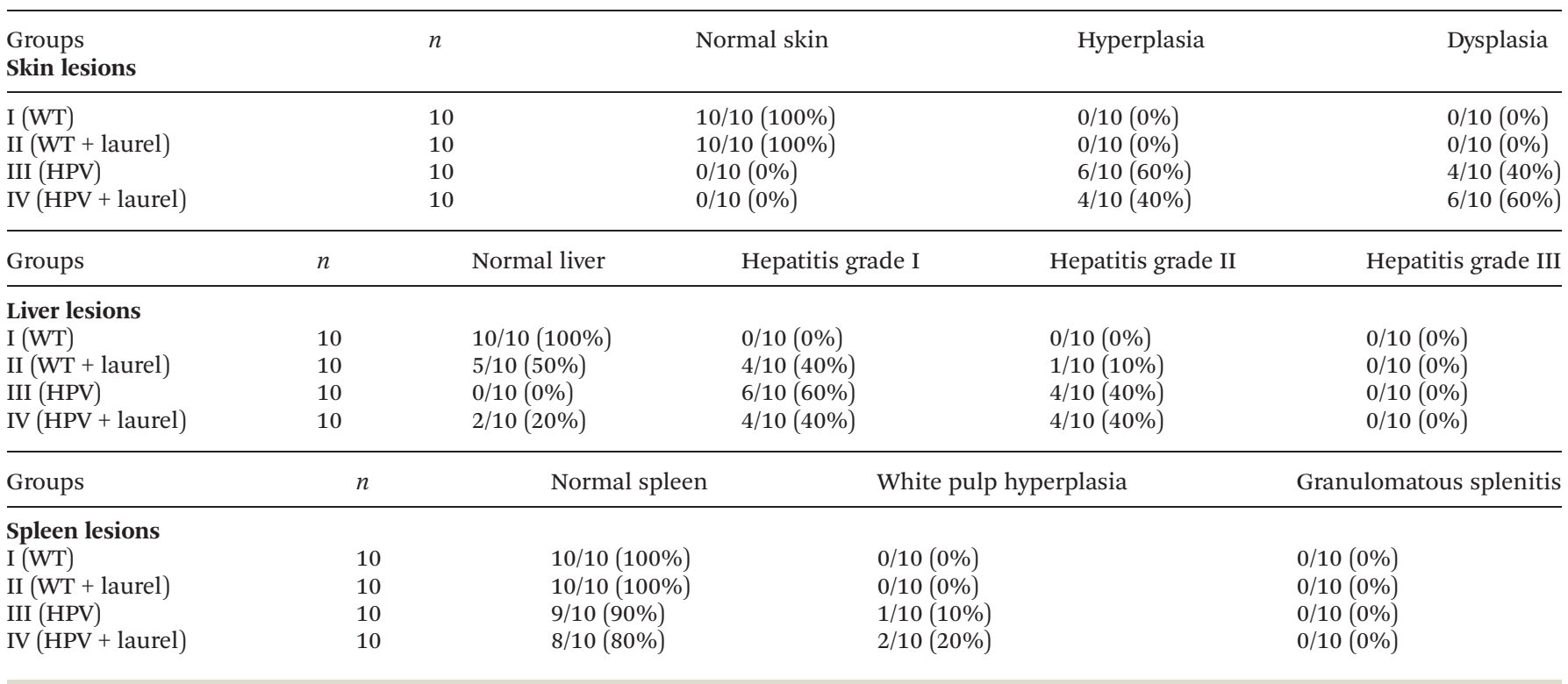

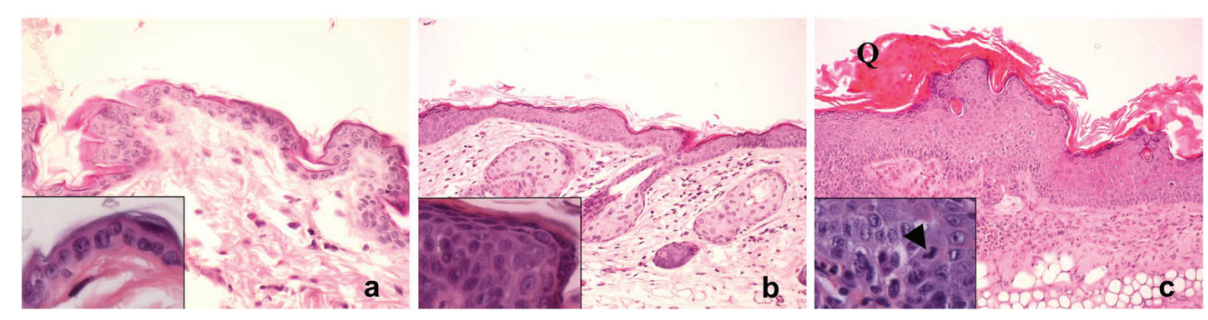

Fig. 3 Histopathological changes induced by HPV16 oncogenes in FVB/n mice, hematoxylin and eosin stain: (a) normal skin histology, 200x. The inset shows the normal epidermis with 1 or 2 cell layers $(400 x)$. (b) Epidermal hyperplasia, 100x. The inset shows the thickened epidermis with up to 7 cell layers $(400 x)$. (c) Epidermal dysplasia, 200x. Note marked parakeratotic hyperkeratosis (Q). The inset shows dysplastic epidermis with suprabasal mitotic activity (arrow) (400x).

Concerning liver samples, the mice of group I showed no hepatic lesions, while half of group II animals showed mild to moderate hepatitis (Table 5 and Fig. 4). Transgenic animals showed hepatic lesions typical of their strain, regardless of the treatment. Concerning the spleen samples, groups I and II presented $100 \%$ normal spleen, while transgenic mice show typical splenic changes (white pulp hyperplasia), regardless of the treatment (Table 5). Concerning hepatic oxidative stress analyses, no significant differences were observed between groups for any of the markers included in this study (Table 6).

\section{Discussion}

The K14HPV16 animal model was developed from FBV/n mice, in order to study the pathophysiology of HPV-induced lesions. HPV is an icosahedral symmetry virus with $55 \mathrm{~nm}$ diameter. The HPV viral genome consists of circular double-stranded DNA, ${ }^{26}$ and encodes multiple genes, including $E 6$ and $E 7$ which are believed to be essential for HPV-mediated cell transformation. ${ }^{27} \mathrm{HPV}$ belongs to the family Papillomaviridae and to the genus alpha-papillomavirus ${ }^{28}$ and is classified into five genera: alpha, beta, gamma, mu and nu. ${ }^{29}$ The alpha-papillo- 


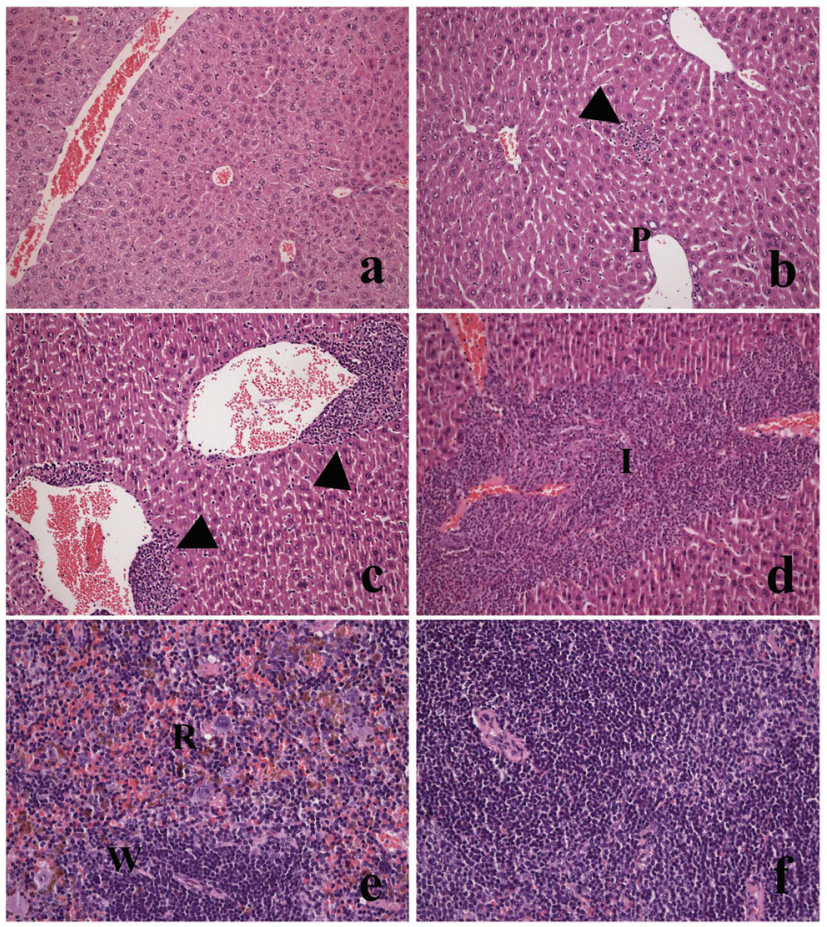

Fig. 4 Hepatic and splenic changes in HPV16-transgenic mice, hematoxylin and eosin: (a) normal liver histology, 100x. (b) Grade I hepatitis, 100x. Note microabscess (arrow) but portal spaces $(P)$ remain free of inflammatory infiltrates. (c) Grade II hepatitis, 100x. Note marked periportal inflammatory infiltrates (arrows). (d) Grade III hepatitis, 100x. Note marked periportal inflammatory infiltrate (I) that forms bridges between adjacent portal areas. (e) Normal splenic histology, showing red (R) and white (W) pulp, 200x. (f) Splenic white pulp hyperplasia with marked predominance of the white pulp component $200 x$.

mavirus genus is divided into low-risk (e.g. types 6 and 11) and high-risk HPV types (e.g. types 16 and 18). While low-risk HPV types are associated with benign lesions such as warts, highrisk HPV may lead to the development of malignant lesions. ${ }^{30}$ HPV 16 and 18 are the most common high-risk types associated with malignant lesions, ${ }^{31}$ such as carcinomas of the anogenital area. ${ }^{32}$ In this murine model, the human promoter of the cytokeratin 14 targets the expression of the HPV16 early genes (including E6 and E7) to the basal layer of the squamous epithelia, ${ }^{33}$ recapitulating HPV16-induced carcinogenesis in the reproductive system and the epidermis. ${ }^{8}$ This model can be used to study the development of viral lesions as well as to evaluate new therapies.

Since ancient times, vegetable extracts have been used for medicinal purposes, providing the treatment of various diseases and often resulting in the production of drugs. Medicinal plants have contributed strongly for the development of new therapeutic strategies through their secondary metabolites (e.g. alkaloids, sterols, terpenes, flavonoids, and saponins $)^{34}$ which interact with cellular targets. ${ }^{35}$

Many plant extracts have anti-inflammatory, antimicrobial and antitumor properties. ${ }^{36}$ The antitumor activity of the
Table 6 Oxidative stress parameters evaluated in the liver of the different experimental groups (mean \pm standard deviation)

\begin{tabular}{|c|c|c|c|c|}
\hline & \multicolumn{4}{|l|}{ Groups } \\
\hline & I (WT) & $\begin{array}{l}\text { II (WT + } \\
\text { laurel) }\end{array}$ & III (HPV) & $\begin{array}{l}\text { IV (HPV + } \\
\text { laurel) }\end{array}$ \\
\hline $\begin{array}{l}\text { ROS } \\
\text { production }^{a}\end{array}$ & $\begin{array}{l}2190 \pm \\
45.49\end{array}$ & $\begin{array}{l}223.20 \pm \\
45.43\end{array}$ & $\begin{array}{l}230.1 \pm \\
53.98\end{array}$ & $\begin{array}{l}230.9 \pm \\
38.62\end{array}$ \\
\hline $\mathrm{Cu} / \mathrm{Zn}-\mathrm{SOD}^{b}$ & $\begin{array}{l}23.44 \pm \\
15.80\end{array}$ & $\begin{array}{l}30.15 \pm \\
17.74\end{array}$ & $\begin{array}{l}29.60 \pm \\
13.97\end{array}$ & $\begin{array}{l}32.24 \pm \\
16.04\end{array}$ \\
\hline $\mathrm{CAT}^{c}$ & $\begin{array}{l}132.9 \pm \\
33.35\end{array}$ & $\begin{array}{l}150.1 \pm \\
41.44\end{array}$ & $\begin{array}{l}146.7 \pm \\
54.30\end{array}$ & $\begin{array}{l}142.3 \pm \\
51.95\end{array}$ \\
\hline $\mathrm{GPx}^{d}$ & $\begin{array}{l}86.64 \pm \\
17.38\end{array}$ & $\begin{array}{l}84.77 \pm \\
18.41\end{array}$ & $\begin{array}{l}93.82 \pm \\
43.66\end{array}$ & $\begin{array}{l}82.14 \pm \\
27.11\end{array}$ \\
\hline $\mathrm{GR}^{e}$ & $\begin{array}{l}31.90 \pm \\
16.00\end{array}$ & $\begin{array}{l}33.96 \pm \\
11.15\end{array}$ & $\begin{array}{l}25.98 \pm \\
13.54\end{array}$ & $\begin{array}{l}28.56 \pm \\
13.09\end{array}$ \\
\hline $\mathrm{GST}^{f}$ & $\begin{array}{l}18.21 \pm \\
5.77\end{array}$ & $22.18 \pm 6.51$ & $\begin{array}{l}21.74 \pm \\
9.45\end{array}$ & $22.74 \pm 7.44$ \\
\hline $\mathrm{GSH}^{g}$ & $\begin{array}{l}18.79 \pm \\
12.40\end{array}$ & $\begin{array}{l}24.58 \pm \\
12.43\end{array}$ & $\begin{array}{l}17.96 \pm \\
8.65\end{array}$ & $\begin{array}{l}16.84 \pm \\
13.41\end{array}$ \\
\hline $\mathrm{GSSG}^{h}$ & $\begin{array}{l}2.40 \pm \\
0.99\end{array}$ & $3.04 \pm 1.21$ & $\begin{array}{l}2.93 \pm \\
1.19\end{array}$ & $3.42 \pm 1.75$ \\
\hline $\mathrm{OSI}^{i}$ & $8.54 \pm 4.6$ & $10.57 \pm 7.67$ & $\begin{array}{l}8.57 \pm \\
5.13\end{array}$ & $5.59 \pm 4.65$ \\
\hline $\mathrm{LPO}^{j}$ & $\begin{array}{l}52.67 \pm \\
20.61\end{array}$ & $\begin{array}{l}65.52 \pm \\
28.55\end{array}$ & $\begin{array}{l}61.33 \pm \\
43.36\end{array}$ & $\begin{array}{l}61.46 \pm \\
31.81\end{array}$ \\
\hline
\end{tabular}

${ }^{a}$ nmol DCF per mg protein. ${ }^{b} \mathrm{U}$ SOD per $\mathrm{mg}$ protein. ${ }^{c} \mathrm{U}$ CAT per mg protein. ${ }^{d}$ nmol NADPH reduced per min mg protein. ${ }^{e}$ nmol NADPH reduced per min $\mathrm{mg}$ protein. ${ }^{f}$ nmol CDNB conjugated per min $\mathrm{mg}$ protein. ${ }^{g} \mu \mathrm{mol}$ GSH per mg protein. ${ }^{h} \mu \mathrm{mol}$ GSSG per mg protein. ${ }^{i} \mathrm{GSH} / \mathrm{GSSG} .{ }^{j} \mu \mathrm{mol}$ MDA per mg protein.

extract of Laurus nobilis L., popularly known as laurel, has been studied in vitro before. ${ }^{5,6}$ This study was designed to evaluate the efficacy of laurel extract against the cutaneous lesions of K14HPV16 transgenic mice, and also to assess its potential in vivo toxicity. This mouse strain shows some particular frailties, such as chronic hepatic and liver inflammation, which could not be improved by laurel extracts.

During the experimental work, no mortality was recorded in any group, and there were also no changes in behavior or other clinical symptoms. These results are interesting, as some of the signs of toxicity commonly associated with natural compounds are mortality and behavioral changes. ${ }^{37,39}$ So, laurel extract administration at this dose did not cause toxicity. The body mass of $\mathrm{HPV}^{+/-}$animals treated with laurel extract was significantly lower than the remaining groups. However, these animals did not show statistically significant differences in their body mass compared to untreated $\mathrm{HPV}^{-/-}$animals. The highest water intake was observed in transgenic animals, a result that has already been described by our team in other experimental studies in which these animals were used. ${ }^{8}$ Concerning the relative masses of organs, the $\mathrm{HPV}^{+/-}$group treated with laurel extract showed statistically significant differences concerning the left kidney, liver, spleen and lungs compared to group II. Again, no changes were observed in $\mathrm{HPV}^{-/-}$ animals treated with laurel extract. Hepatomegaly is a typical finding for this strain, ${ }^{8}$ reflecting chronic hepatic inflammation. In this context, the significance of minor to mild 
hepatitis, observed in 50\% of laurel-treated wild-type mice, remains unclear. Laurel-treated animals didn't show significant changes in the serum levels of hepatic transaminases, compared with matched untreated controls, nor did they show increased hepatic oxidative stress. The weight loss and increased hepatic weight observed in laurel-treated $\mathrm{HPV}^{+/-}$ mice may reflect a negative impact of laurel in these already fragile animals. This would be in agreement with previous in vitro results, ${ }^{11}$ showing that laurel extracts exert some cytotoxicity against hepatocytes. Similarly, the histological changes observed in wild-type animals may indicate a hepatotoxic effect. However, this was not accompanied by any of the biochemical markers employed and evaluated oxidative stress parameters. Hepatic toxicological aspects deserve to be confirmed in future in vivo studies, using a dose-response approach.

K14HPV16 mice develop epidermal hyperplasia that progresses to dysplasia and carcinoma in situ (CIS) lesions, ultimately evolving into invasive cancer. ${ }^{16}$ Progression from the hyperplastic to the dysplastic stage typically occurs between 20 and 30 of age and is accompanied by increased cell proliferation and multiple immunological and pro-inflammatory changes. ${ }^{12,13,16,17,38}$ The percentage of lesions identified in both transgenic groups $\left(\mathrm{HPV}^{+/-}\right.$treated and untreated) was similar, suggesting that the laurel extract had no influence on the progression of HPV16-induced lesions, in this in vivo model. These results are in contrast to the in vitro assay previously conducted on a cervical cancer cell line (HeLa) by Dias et $a{ }^{11}{ }^{11}$ This cancer cell line is related to HPV18, ${ }^{40}$ while the present mouse model is transgenic for HPV16, which may perhaps explain this difference, at least in part. In order to confirm the potential activity of this laurel extract against lesions caused by HPV18, in vivo studies using an HPV18-transgenic mouse strain are recommended. Additional studies using HPV16-transgenic mice should employ a range of higher laurel extract doses, and other routes of administration, in order to confirm whether these are active against HPV-induced lesions.

\section{Conclusion}

Overall, the laurel extract was well tolerated by the animals. However, no efficacy against HPV16-induced lesions was observed. Further studies are necessary to understand if different doses of this extract would cause some effects.

\section{Author contributions}

B. Medeiros-Fonseca, Magda S.S. Moutinho and V.F. Mestre conducted the experiments with live animals and wrote the manuscript. B. Colaço, M.J. Pires and T. Martins participated in animals' sacrifice and samples' processing and wrote the manuscript. R.M. Gil da Costa performed the experimental design, performed the histopathological evaluation of samples and wrote the manuscript. M.J. Neuparth performed serum biochemistry and wrote the manuscript. R. Medeiros and M. M.S.M. Bastos participated in data analysis and wrote the manuscript. Maria Inês Dias, Lillian Barros, and Isabel C.F.R. Ferreira performed Laurus nobilis L. extract preparation and characterization and wrote the manuscript. L. Félix, C. Venâncio performed the hepatic oxidative stress studies and wrote the manuscript. L.M. Antunes supervised animals' wellbeing and wrote the manuscript. P.A. Oliveira performed the experimental design, supervised the animal experiments, participated in animals' sacrifice, performed the statistical analysis, and wrote the manuscript.

\section{Conflicts of interest}

All authors declare no actual, potential, or perceived conflict of interest that would prejudice the impartiality of the article.

\section{Acknowledgements}

This work was supported by: Integrative Research in Environment, Agro-Chains and Technology no. NORTE-010145-FEDER-000017, in its line of research entitled ISAC, cofinanced by the European Regional Development Fund (ERDF) through NORTE 2020 (North Regional Operational Program 2014/2020). European Investment Funds by FEDER/COMPETE/ POCI- Operational Competitiveness and Internationalization Programme, under Project POCI-01-0145-FEDER-006958 and National Funds by FCT - Portuguese Foundation for Science and Technology, under the project UID/AGR/04033/2013. This study was also funded by Liga Portuguesa Contra o Cancro, by the Research Center of the Portuguese Institute of Oncology of Porto (CI-IPOP 37-2016), by project POCI-01-0145FEDER-006939 (Laboratory for Process Engineering, Environment, Biotechnology and Energy - LEPABE), project POCI-01-0145-FEDER-006958 and UID/AGR/04033/2013, funded by FEDER funds through COMPETE2020 - Programa Operacional Competitividade e Internacionalização (POCI) and by national funds through FCT - Fundação para a Ciência e a Tecnologia; Rui M. Gil da Costa was funded by grant number SFRH/BPD/85462/2012 from FCT, funded by the Portuguese Government and the Social European Fund. The authors are also grateful to FCT, Portugal and FEDER under Programme PT2020 for financial support to CIMO (UID/AGR/ 00690/2013), and to the Interreg España-Portugal for financial support through the project 0377_Iberphenol_6_E.

We appreciate the technical support of Vanessa Silva.

\section{References}

1 L. Caputo, et al., Laurus nobilis: Composition of Essential Oil and Its Biological Activities, Molecules, 2017, 22, 930. 
2 E. Y. Qnais, et al., Antidiarrheal activity of Laurus nobilis L. leaf extract in rats, J. Med. Food, 2012, 15, 51-57.

3 M. A. Fard and A. Shojaii, Efficacy of Iranian Traditional Medicine in the Treatment of Epilepsy, BioMed Res. Int., 2013, 1-8.

4 M. Sayyah, et al.,Anticonvulsant activity of the leaf essential oil of Laurus nobilis against pentylenetetrazole- and maximal electroshock-induced seizures, Phytomedicine, 2002, 9, 212-216.

5 A. M. Saab, et al., Laurus nobilis L. seed extract reveals collateral sensitivity in multidrug-resistant P-glycoproteinexpressing tumor cells, Nutr. Cancer, 2015, 67, 664-675.

6 M. E. M. Saeed, et al., Cytotoxicity of South-African medicinal plants towards sensitive and multidrug-resistant cancer cells, J. Ethnopharmacol., 2016, 186, 209-223.

7 G. M. Cragg and D. J. Newman, Plants as a source of anticancer agents, J. Ethnopharmacol., 2005, 100, 72-79.

8 R. M. Gil da Costa, et al., HPV16 induces a wasting syndrome in transgenic mice: Amelioration by dietary polyphenols via NF-кB inhibition, Life Sci., 2017, 169, 11-19.

9 R. Grzanna, et al., Ginger-An Herbal Medicinal Product with Broad Anti-Inflammatory Actions, J. Med. Food, 2005, 8, 125-132.

$10 \mathrm{~J}$. W. Hong, et al., Anti-inflammatory activity of cinnamon water extract in vivo and in vitro LPS-induced models, $B M C$ Complementary Altern. Med., 2012, 12, 237-244.

11 M. I. Dias, et al., Two - Dimensional PCA Highlights the Differentiated Antitumor and Antimicrobial Activity of Methanolic and Aqueous Extracts of Laurus nobilis L. from Different Origins, BioMed Res. Int., 2014, 1-10.

12 J. M. Arbeit, et al., Progressive squamous epithelial neoplasia in K14-human papillomavirus type 16 transgenic mice, J. Virol., 1994, 68, 4358-4368.

13 C. Santos, et al., Ptaquiloside from bracken (Pteridium spp.) inhibits tumour-infiltrating CD8+T cells in HPV-16 transgenic mice, Food Chem. Toxicol., 2016, 97, 277-285.

14 M. I. Dias, et al., Nutritional and antioxidant contributions of Laurus nobilis L. leaves: would be more suitable a wild or a cultivated sample?, Food Chem., 2014, 156, 339-346.

15 S. M. F. Bessada, et al., Phenolic profile and antioxidant activity of Coleostephus myconis (L.) Rchb.f.: An underexploited and highly disseminated species, Ind. Crops Prod., 2016, 89, 45-51.

16 I. Paiva, et al., MicroRNA-21 expression and susceptibility to HPV-induced carcinogenesis - role of microenvironment in K14-HPV16 mice model, Life Sci., 2015, 128, 8-14.

17 I. Paiva, et al., A Role for microrna-155 Expression in Microenvironment Associated to hpvinduced Carcinogenesis in K14-HPV16 Transgenic Mice, PLoS One, 2015, 10, e0116868.

18 D. Forbes, et al., Euroguide on the accommodation and care of animals used for experimental and other scientific purposes,
Federation of European Laboratory Animal Science Associations, London, 2007.

19 C. P. Lebel and S. C. Bondy, Sensitive and rapid quantitation of oxygen reactive species formation in rat synaptosomes, Neurochem. Int., 1990, 17, 435-440.

20 I. Durak, et al., A methodological approach to superoxide dismutase (SOD) activity assay based on inhibition of nitroblue tetrazolium (NBT) reduction, Clin. Chim. Acta, 1993, 214, 103-104.

21 H. Aebi, Catalase in vitro, Methods Enzymol., 1984, 105, 121-126.

22 D. E. Paglia and W. N. Valentine, Studies on the quantitative and qualitative characterization of erythrocyte glutathione peroxidase, J. Lab. Clin. Med., 1967, 70, 158-169.

23 I. Carlberg and B. Mannervik, Glutathione reductase, Methods Enzymol., 1985, 113, 484-490.

24 D. A. Vessey and T. D. Boyer, Differential activation and inhibition of different forms of rat liver glutathione S-transferase by the herbicides 2,4-dichlorophenoxyacetate (2,4-D) and 2,4,5-trichlorophenoxyacetate (2,4,5-T), Toxicol. Appl. Pharmacol., 1984, 73, 492-499.

25 S. P. Gartaganis, et al., Evidence for oxidative stress in lens epithelial cells in pseudoexfoliation syndrome, Eye, 2007, 21, 1406-1411.

26 R. Faridi, et al., Oncogenic potential of Human Papillomavirus (HPV) and its relation with cervical cancer, Virol. J., 2011, 8, 269-276.

27 V. M. Williams, et al., HPV-DNA integration and carcinogenesis: putative roles for inflammation and oxidative stress, Future Virol., 2011, 6, 45-57.

28 H. U. Bernard, et al., Classification of papillomaviruses (PVs) based on $189 \mathrm{PV}$ types and proposal of taxonomic amendments, Virology, 2010, 401, 70-79.

29 E. M. de Villiers, et al., Classification of papillomaviruses, Virology, 2004, 324, 17-27.

30 M. Koparal, et al., Human papilloma virus, J. Turgut Ozal Med. Cent., 2016, 23, 353-356.

31 P. C. Giraldo, et al., Prevenção da infecção por hpv e lesões associadas com o uso de vacinas, J. Bras. Doenças Sex. Trans., 2008, 20, 132-140.

32 C. de Martel, et al., Global burden of cancers attributable to infections in 2008: a review and synthetic analysis, Lancet Oncol., 2012, 13, 607-615.

33 A. Masset, et al., Unimpeded skin carcinogenesis in K14-HPV16 transgenic mice deficient for plasminogen activator inhibitor, Int. J. Cancer, 2011, 128, 283-293.

34 M. A. Motaleb, Selected Medicinal Plants of Chittagong Hill Tracts, International Union for Conservation of Nature, Dhaka, Bangladesh, 2011.

35 W. C. A. Firmo, et al., Contexto histórico, uso popular e concepção científica sobre plantas medicinais, Cad. Pesqui., 2011, 18, 90-95.

36 M. M. Cowan, Plant Products as Antimicrobial Agents, Clin. Microbiol. Rev., 1999, 12, 564-582. 
37 R. Arantes-Rodrigues, et al., High doses of olive leaf extract induce liver changes in mice, Food Chem. Toxicol., 2011, 49, 1989-1997.

38 M. S. S. Moutinho, et al., Curcumin and Rutin Down-regulate Cyclooxygenase-2 and Reduce Tumor-associated Inflammation in HPV16-Transgenic Mice, Anticancer Res., 2018, 38, 1461-1466.
39 K. Seedorf, et al., Identification of early proteins of the human papilloma viroses type 16 (HPV 16) and type 18 (HPV 18) in cervical carcinoma cells, EMBO J., 1987, 6, 139.144.

40 N. C. Popescu, et al., Integration sites of human papillomavirus 18 DNA sequences on HeLa cell chromosomes, Cytogenet. Cell Genet., 1987, 44, 58-62. 